\title{
ESPECIFICAÇÃO DA VIDA ÚTIL DOS SISTEMAS CONSTRUTIVOS A PARTIR DA NBR 15575, SEGUNDO A ABORDAGEM DE PROJETOS
}

\section{USEFUL LIFE SPECIFICATIONS OF THE CONSTRUCTIVE SYSTEMS ACCORDING TO 15575, ACCORDING TO THE PROJECT APPROACH}

\author{
Claudivana Sistherenn Pagliari 1 \\ Universidade Comunitária da Região de Chapecó, Chapecó, SC, Brasil, clau-sistherenn@unochapeco.edu.br \\ Marcelo Fabiano Costella ${ }^{2}$ \\ Universidade Comunitária da Região de Chapecó e Faculdade Meridional IMED, Chapecó, SC, Brasil, \\ costella@unochapeco.edu.br
}

Sílvio Edmundo Pilz ${ }^{3}$

Universidade Comunitária da Região de Chapecó, Chapecó, SC, Brasil, silvio@ unochapeco.edu.br

\section{Resumo}

Tendo em vista a necessidade dos projetistas em realizar especificações da vida útil dos sistemas construtivos que compõe uma edificação habitacional, a presente pesquisa tem como objetivo analisar as especificações que estão sendo elaboradas por projetistas. $\mathrm{O}$ método de pesquisa consistiu em uma pesquisa de campo, primeiramente foi realizado um levantamento com profissionais da área de projeto por meio de questionário online dividido em questões diretas e indiretas. Posteriormente, avaliaram-se projetos e memoriais para verificar o nível de especificação atual. Por fim, realizou-se a investigação das especificações dos materiais por parte de seus fabricantes por meio de buscas em páginas da internet de fabricantes e contatos via e-mail dos subsistemas: pisos, revestimentos internos e externos e impermeabilização. Os subsistemas selecionados são considerados básicos e de grande influência visual em uma edificação, tendo como base o Anexo C da NBR 15575-1. Dentre os resultados obtidos, foi possível constatar a falta de informações disponibilizadas pelos fabricantes dos materiais a serem especificados nos projetos, sendo que a maioria dos fabricantes dos materiais selecionados nessa pesquisa não informam dados de durabilidade e vida útil, o que impossibilita os projetistas de cumprirem suas premissas perante a norma de desempenho.

Palavras-chave: Vida útil. Norma de Desempenho. Especificações de sistemas construtivos.

\begin{abstract}
Considering the need for designers to develop useful life specifications of the constructive systems that make up a residential building, this study seeks to analyze the specs that are being developed by designers. The research method consisted of a field study. In the first stage, a survey was carried out with design professionals through an online questionnaire divided into direct and indirect questions. Subsequently, designs and project specifications were evaluated to verify the current specification level. Finally, the material specifications of the manufacturers were assessed through searches on the websites of manufacturers and contacts via e-mail about the subsystems: floors, internal and external coatings and waterproofing systems. The selected subsystems are considered essential and of great visual influence on a building, based on Annex C of NBR 15575-1. Among the results, a lack of information provided by the manufacturers about the materials to be specified in the design phase could be observed. That is, most material manufacturers selected for this study didn't provide data related to durability and useful life, which makes it impossible for designers to comply with the assumptions of the performance standard.
\end{abstract}

Keywords: Useful life. Performance standard. Specifications of the constructive systems.

\section{How to cite this article:}

PAGLIARI, Claudivana Sistherenn; COSTELLA, Marcelo Fabiano; PILZ, Silvio Edmundo. Especificação da vida útil dos sistemas construtivos a partir da NBR 15575, segundo a abordagem de projetos. PARC Pesquisa em Arquitetura e Construção, Campinas, SP, v. 9, n. 1, p. 47-56, mar. 2018. ISSN 1980-6809. Disponível em: <https://periodicos.sbu.unicamp.br/ojs/index.php/parc/article/view/8648828>. Acesso em: 10 maio 2018. doi:https://doi.org/10.20396/parc.v9i1.8648828. 


\section{Introdução}

A Norma de Desempenho NBR 15575 (ABNT, 2013 a,b,c,d,e,f) apresenta diversas considerações a respeito da vida útil das edificações e dos seus sistemas e subsistemas construtivos, buscando garantir que as edificações obtenham um desempenho mínimo.

O estudo e uso adequado de informações de vida útil dos materiais e componentes das construções habitacionais permitem a obtenção de edifícios de melhor qualidade. Conforme ressaltam Possan e Demoliner (2013), os profissionais devem considerar a vida útil mínima dos elementos e sistemas ainda na fase de projeto da edificação, buscando garantir que estes desempenhem suas funções durante a vida útil especificada.

A partir da publicação da norma de desempenho (ABNT, 2013 a,b,c,d,e,f), construtoras, projetistas e profissionais envolvidos com a construção de edificações habitacionais estão enfrentando algumas dificuldades em adequar-se às determinações realizadas pela norma. Segundo Freitas, Schmid e Silva (2016), os projetos de construção convencionais apresentam disparidades entre vida de uso da edificação e ciclo de vida dos materiais. Desta forma, tornando evidente que algo não está seguindo os padrões normativos.

Tendo em vista os problemas relatados, o presente trabalho tem como objetivo investigar projetistas e fornecedores a respeito de seus conhecimentos e atitudes com relação à norma de desempenho NBR 15575, especialmente como estão especificando em seus projetos e memoriais a vida útil de projeto, a manutenção de projeto e as especificações dos materiais.

\section{Revisão bibliográfica}

\section{Conceitos de vida útil e durabilidade na construção}

A norma de desempenho NBR 15575-1 (ABNT, 2013a) tem como principal objetivo promover a qualidade do setor da construção civil com atenção sobre a vida útil da edificação que busca prolongar o tempo de vida das construções habitacionais.

De acordo com a NBR 15575-1 (ABNT, 2013a), a vida útil (VU) de um sistema construtivo é o período de tempo em que uma edificação executa as atividades para as quais foi projetada e construída. No entanto, vida útil de projeto (VUP) é o período estimado de tempo para o qual um sistema é projetado, ou seja, a VUP é uma estimativa teórica do período que compõe o tempo de vida útil.

A vida útil de um produto não pode ser confundida com o prazo de garantia do produto, sendo que conforme a NBR 15575-1 (ABNT, 2013a), garantia do produto são condições dadas pelo fornecedor por meio de certificados de garantia para reparos, recomposição, devolução ou substituição do produto adquirido.

O conceito de vida útil de projeto, inserido pela NBR 15575-1 (ABNT, 2013a), repercute na durabilidade das edificações, seus sistemas e na manutenção embutida nesse conceito.

$\mathrm{O}$ uso adequado da vida útil dos materiais e seus componentes permite a obtenção de edifícios de melhor qualidade, que contribuem com a sustentabilidade da indústria da construção, tornando-os mais econômicos e beneficiando um grande número de pessoas (HERNÁNDEZ-MORENO, 2011).

Oliveira, Fontenelle e Mitidieri Filho (2014, p. 54) afirmam que, "a durabilidade pode ser tomada genericamente como o período no qual o produto mantém as características ou funções que lhe foram atribuídas, atendendo o desempenho esperado ao longo de sua vida útil.” Porém, segundo a NBR 15575-6 (ABNT, 2013f), para manter a capacidade funcional do produto durante sua vida útil de projeto é necessário que os sistemas sejam submetidos a intervenções periódicas de manutenção e conservação.

\section{A manutenção e sua influência na durabilidade dos materiais}

A norma de desempenho (ABNT, 2013 a,b,c,d,e,f) apresenta dois tipos distintos de manutenção, a de Projeto e de Rotina. A Manutenção de Rotina envolve a realização de manutenções periódicas da edificação pelo usuário, através de um manual de uso, operação e manutenção da edificação com informações do fornecedor e do construtor. A Manutenção de Projeto é de responsabilidade do projetista e está relacionada com as manutenções dos sistemas da edificação como, por exemplo, a manutenção do sistema hidrossanitário que se encontra dentro de um shaft da edificação.

Quando o material empregado na edificação é novo, ele atende aos requisitos de seu desempenho, porém com o passar do tempo, de acordo com Del Mar (2015), verificam-se desgastes e deteriorações, tornando necessária a realização de manutenções. Essas manutenções têm como objetivo fazer com que o material, produto ou equipamento atendam aos requisitos de desempenho especificados no projeto.

De acordo com a NBR 15575-6 (ABNT, 2013f), a vida útil dos componentes de um sistema depende da agressividade do meio ambiente, das características intrínsecas dos materiais e dos solos, podendo apresentar vida útil menor do que as estabelecidas como vida útil de projeto. Deste modo, o projeto deve constar o prazo de substituições e manutenções pertinentes. 
Ortega, Serrano e Fran (2015) destacam que para a elaboração de um programa de manutenção satisfatório e economicamente viável é necessária uma estimativa da vida útil dos elementos que compõe a construção de um edifício e seus materiais de serviço. Porém, esta é uma das dificuldades dos projetistas, pois estas especificações deveriam ser disponibilizadas pelo fornecedor, o que geralmente não acontece.

\section{Elaboração de projetos e a determinação da vida útil}

Segundo Sanches e Fabricio (2008), é na fase de projeto que são tomadas decisões com maiores repercussões ao longo do ciclo de vida de uma edificação. Deste modo, este período é considerado de fundamental importância para o futuro desempenho de qualidade e reduções de custos de uso, manutenção e operação da edificação.

A NBR 15575-1 (ABNT, 2013a) incumbe o projetista, na fase de projeto de uma edificação, como responsável por determinar a vida útil de projeto de cada sistema que compõe a construção. Assim, é dele o dever de estabelecer quais materiais, produtos e processos atendem ao desempenho mínimo.

De acordo com a CBIC (2013), o tempo de vida útil considerado pela vida útil de projeto é influenciado pela eficiência das manutenções realizadas na edificação. Desta forma, a vida útil de projeto mínima estabelecida por projetistas será atingida por meio da realização de ações de manutenção de rotina e de projeto, seguindo os padrões instituídos pela NBR 5674 (ABNT, 1999), do contrário, sua vida útil real será comprometida.

Apesar de não ser de responsabilidade dos projetistas a execução das manutenções, eles precisam especificar as orientações de manutenção dos sistemas por eles projetados. Deste modo, ao adquirir um imóvel o usuário deve exigir informações sobre a vida útil da edificação e as manutenções de rotina e de projeto dos componentes e sistemas da edificação (SANTOS, 2011).

De acordo com a NBR 15575-2 (ABNT, 2013b), os componentes da edificação devem ser projetados de modo que quando utilizados conforme preconizado em projeto e submetidos a intervenções periódicas de manutenção e conservação, seguindo instruções contidas no manual de operação, uso e manutenção, devem manter sua capacidade funcional durante toda a vida útil de projeto.

Em diversas situações da construção civil o projetista não é quem controla a execução e fiscaliza na obra os materiais que estão sendo utilizados na edificação, deste modo Del Mar (2015, p. 54) afirma que "a responsabilidade dos projetistas é limitada aos defeitos intrínsecos a seu projeto e não pela falha da execução, quando dela não participem".
Segundo a NBR 15575-1 (ABNT, 2013a), a tendência entre projetistas e construtores é utilizar produtos com menor custo inicial, sem a definição da VUP, porém menos duráveis, causando maiores custos de manutenção e, consequentemente, maior custo global da edificação. Geralmente os materiais de maior qualidade apresentam um custo maior, o que faz os responsáveis pelo projeto e pela obra optarem por materiais mais baratos e, consequentemente, de menor qualidade e desempenho.

Os responsáveis devem buscar melhorar a relação custo e benefício da edificação, por meio da determinação de manutenções e vida útil de projeto coerente com as especificações da edificação.

Porém, Del Mar (2015) também destaca que, em casos onde o projetista e o construtor especificaram materiais de menor qualidade, estes não devem ser responsabilizados pela diferença de desempenho dos materiais, pois estas especificações foram aceitas pelo contratante.

Os materiais a serem utilizados na edificação devem ser selecionados tendo como base diversos critérios. Segundo Peças et al. (2013), estes critérios são: desempenho técnico, econômico e ambiental. Tendo estas características como base, é requerido uma visão geral da utilização, aplicabilidade e do desempenho necessário para o material.

Straub (2012) também afirma que é de fundamental importância, para projetistas e responsáveis pela construção, tomar conhecimento do tempo de vida útil dos componentes da construção, ou seja, seus ciclos de substituições. Esse conhecimento torna possível o planejamento da construção, no âmbito de uma previsão financeira para suas futuras manutenções.

\section{Os fabricantes e a determinação da vida útil}

Na questão dos fabricantes de materiais, a NBR 15575-1 (ABNT, 2013a) menciona que para a VUP mínima possa ser atingida é necessário que os fabricantes de materiais e componentes que serão utilizados nas construções informem em documentação técnica as recomendações necessárias para a manutenção corretiva e preventiva. Entretanto, Zarzar Júnior (2007) comenta que, apesar do conhecimento sobre as características dos produtos, alguns fabricantes desconhecem o desempenho dos seus produtos, devido à falta de ensaios e comprovações.

Progressivamente será necessário que fabricantes de materiais e componentes da construção busquem métodos sistemáticos para avaliar os riscos de deterioração prematura dos produtos existentes (LACASSE; SJOSTROM, 2004). Estes dados devem levar em consideração os efeitos climáticos específicos e as 
condições de exposição mais vulneráveis dos produtos nos sistemas especificados.

Segundo Daniotti e Spagnolo (2008), os fabricantes dos produtos utilizados na construção civil raramente tornam públicas as informações relacionadas à vida útil de serviço e durabilidade de seus produtos, apenas são armazenadas em declarações/bases de dados da empresa.

Chevalier et al. (2005) afirma que a fonte primária mais confiável de informações sobre a vida útil do material é o fabricante do produto. Porém, o fabricante não tem o dever de saber onde este material será utilizado, ele apenas informa um número de situações gerais limitadas e restritas de aplicações. Deste modo, nem sempre as características do produto serão aplicáveis à situação em que o projetista irá utilizá-lo.

Santos (2010) ressalta que, para determinado conjunto de condições, alguns materiais tem uma vida útil mais longa do que outros, pois as propriedades dos materiais apresentadas pelo fabricante não estão necessariamente relacionadas à durabilidade em todas as condições ambientais, físicas, químicas, etc.

Porém, conforme destaca a CBIC (2015), o fabricante deveria informar todas as características técnicas do produto, cuidados no transporte, armazenamento, instalação e operação, periodicidade e formas de inspeção, materiais e processos a serem adotados nas manutenções preventivas e corretivas, formas de assistência técnica e prazos de garantia, condições para manutenção ou perda da garantia.

\section{Durabilidade e vida útil de sistemas construtivos}

Segundo Del Mar (2015, p. 87), "quando se analisa a importância dos vícios e defeitos, é preciso ter visão sistêmica da edificação". Deste modo, pode-se compreender que um edifício é composto por diversos sistemas, aonde os problemas nem sempre virão de um único material empregado, mas sim das consequentes relações entre as partes componentes do mesmo sistema.

Tendo como base a norma de desempenho NBR 155751(ABNT, 2013a), observou-se que a vida útil de projeto de uma edificação é atingida quando esta dura o período de tempo para qual foi projetada, sendo que a VUP definida não poderá ser maior que os valores apresentados na Tabela 1 .

Tabela 1 - Vida útil de projeto (VUP)

\begin{tabular}{lc}
\multicolumn{1}{c}{ Sistema } & VUP mínima em anos \\
\hline Estrutura & $>=50$ Conforme ABNT NBR 8681 \\
\hline Pisos internos & $>=13$ \\
\hline Vedação vertical externa & $>=40$ \\
\hline Vedação vertical interna & $>=20$ \\
\hline Cobertura & $>=20$ \\
\hline Hidrossanitários & $>=20$
\end{tabular}

Fonte: NBR 15575-1 (ABNT, 2013a)
Porém a afirmação da NBR 15575-1 (ABNT, 2013a, p. 32) de que "decorridos $50 \%$ dos prazos da VUP descritos na Tabela [...], desde que não exista histórico de necessidade de intervenções significativas, considera-se atendido o requisito da VUP [...]." coloca o conceito de vida útil de projeto questionável.

Ao analisar esta afirmação da norma pode-se constatar que a VUP mínima é na realidade a metade da VUP mínima estabelecida pela norma, o que gera uma contradição na norma de desempenho. Deixando assim, projetistas e usuários com dificuldades em seguir a norma.

Santos e Hippert (2016) destacam em seu trabalho a importância do atendimento à manutenibilidade, ou seja, o grau de facilidade com que um sistema, elemento ou componente é conservado no estado de desempenho em que execute as funções demandadas pelo projeto. Desta forma, é necessário que as informações de manutenção sejam consideradas em projeto.

Para facilitar os trabalhos dos projetistas e a segurança dos futuros usuários da edificação é de grande valia um estudo sobre vida útil de projeto de uma edificação, a qual deve possuir uma descrição das boas práticas de manutenção de projeto e especificação dos sistemas construtivos de acordo com a norma de desempenho.

\section{Procedimentos metodológicos}

Os procedimentos metodológicos consistiram no desenvolvimento de uma pesquisa de campo realizada em três etapas. Primeiramente, realizou-se o envio de um questionário por meio eletrônico para projetistas da construção civil, considerando que não foi realizada nenhuma conferência da consistência de seus e-mails. A delimitação da amostra de profissionais teve como base membros de associações e conselhos da região oeste de Santa Catarina.

Em um segundo momento, entrou-se em contato por meio telefônico com alguns dos projetistas da amostra, sendo estes com maior influência e destaque no setor de projetos da região. O objetivo desta segunda aproximação visou averiguar sobre a falta de interesse em responder o questionário encaminhado e solicitar a disponibilidade de exemplares de seus memoriais e projetos. A análise dos memoriais e projetos compreendeu a segunda etapa do estudo.

A terceira etapa do estudo abrangeu uma investigação das especificações dos materiais por parte de seus fabricantes por meio de buscas em páginas da internet de fabricantes e contatos via e-mail. Deu-se ênfase para os subsistemas: pisos, revestimentos internos e externos e impermeabilização, por serem considerados básicos e de 
grande influência visual em uma edificação. Esta escolha foi baseada no Anexo C da NBR 15575-1.

\section{Aplicação de questionários}

O levantamento de dados junto aos projetistas foi realizado por meio de questionário online, contemplando uma base de dados de 420 profissionais associados à Associação de Engenheiros e Arquitetos do Oeste (AEAO), Núcleo de Decorações Chapecó (Núcleo D), Conselho de Arquitetura e Urbanismo de Santa Catarina (CAU-SC) e Conselho Regional de Engenharia e Agronomia de Santa Catarina (CREA-SC). Esta base abrange, pelo menos, $80 \%$ dos profissionais de Engenharia Civil e Arquitetura da região de Chapecó, SC.

Por meio deste levantamento, buscou-se verificar o conhecimento dos profissionais envolvidos com projetos de edificações habitacionais, a respeito da manutenção de projeto, o que estão especificando em seus memoriais, quais as dificuldades encontradas para realizar estas especificações e quais manutenções de projeto consideram fundamentais para atingir a vida útil da edificação. Estas indagações estão presentes no questionário composto por oito questões, sendo três objetivas (Sim/Não/Em alguns) e cinco discursivas, como pode ser observado no Quadro 1, sendo que esta diferenciação teve como objetivo possibilitar ao entrevistado descrever suas ideias, dúvidas e conhecimentos.

O levantamento contemplou profissionais da área de projetos, engenheiros civis e arquitetos, especializados na elaboração dos seguintes projetos: estruturais, hidrossanitários, preventivos de incêndio e arquitetônicos. Entretanto, em função da grande dificuldade em obter respostas online destes profissionais, fato que resultou em um baixo número de respostas, entrou-se em contato via meio telefônico com 22 profissionais. Buscou-se profissionais que, de alguma maneira, tinham envolvimento anterior com a norma de desempenho, seja por terem participado de curso promovido pela AEAO ou por estarem vinculados a alguma Instituição de Ensino.

\section{Análise de memoriais e projetos}

A segunda etapa consistiu na análise e interpretação de projetos e memoriais recentemente elaborados por projetistas de sistemas estruturais, hidrossanitários, preventivos e arquitetônicos da região de Chapecó/SC.

Para a obtenção dos memoriais e projetos, entrou-se em contato por meio telefônico com 10 projetistas, que participaram da etapa anterior, solicitando a contribuição documental com a pesquisa. A amostra final nessa etapa do estudo foi de 5 projetos com o respectivo memorial, sendo 3 projetos arquitetônicos e 2 projetos de cálculo estrutural em concreto armado. Nessa etapa não foram analisados projetos hidrossanitários e preventivos de incêndio.

Através da análise dos memoriais e projetos, observaramse os métodos de especificação dos materiais e as manutenções sugeridas para os sistemas construtivos.

\begin{tabular}{|c|c|}
\hline 1 & $\begin{array}{l}\text { A vida útil de projeto (VUP) é uma estimativa do período do } \\
\text { tempo de vida útil em que o projetista é responsável pelas } \\
\text { decisões com maiores repercussões ao longo do ciclo de vida } \\
\text { da edificação. Na elaboração dos seus projetos, está realizando } \\
\text { especificações considerando à vida útil de projeto? } \\
\text { (Sim/Não/Em alguns) }\end{array}$ \\
\hline 2 & $\begin{array}{l}\text { A Norma de Desempenho (NBR 15575), estabelece os valores } \\
\text { de vida útil de projeto mínima, intermediária e superior dos } \\
\text { sistemas de uma edificação. O que você está fazendo ou faria } \\
\text { de diferente para atender os prazos de vida útil de projeto } \\
\text { estabelecido na Norma? (Discursiva) }\end{array}$ \\
\hline 3 & $\begin{array}{c}\text { É função dos projetistas estabelecer quais materiais atendem ao } \\
\text { desempenho mínimo da edificação. Você está realizando } \\
\text { alguma dessas especificações em seus memoriais descritivos? } \\
\text { (Discursiva) }\end{array}$ \\
\hline 4 & $\begin{array}{l}\text { Quais materiais você especifica ou deveria estar especificando } \\
\qquad \text { em seus projetos? (Discursiva) }\end{array}$ \\
\hline 5 & $\begin{array}{l}\text { A norma também ressalta que é de responsabilidade do } \\
\text { fornecedor do sistema caracterizar o seu desempenho e, } \\
\text { consequentemente, dos materiais empregados. Você tem a } \\
\text { prática de consultar com o fabricante a vida útil dos materiais } \\
\text { especificados nos seus projetos? Se sim, para quais materiais } \\
\text { encontrou a especificação? (Discursiva) }\end{array}$ \\
\hline 6 & $\begin{array}{l}\text { A Norma de Desempenho apresenta dois tipos distintos de } \\
\text { manutenção, de Projeto e de Rotina. Manutenção de Rotina, } \\
\text { envolve a realização de manutenções periódicas da edificação } \\
\text { pelo usuário, através de um manual de uso, operação e } \\
\text { manutenção da edificação com informações do fornecedor e do } \\
\text { construtor. Manutenção de Projeto é de responsabilidade do } \\
\text { projetista e está relacionada com as manutenções dos sistemas } \\
\text { da edificação, como por exemplo a manutenção do sistema } \\
\text { hidrossanitário, que se encontra dentro de um shaft. Você } \\
\text { conhecia a diferença entre Manutenção de Projeto e a } \\
\text { Manutenção de Rotina? (Discursiva) }\end{array}$ \\
\hline 7 & $\begin{array}{l}\text { Tendo em vista o período de vida útil de projeto determinado na } \\
\text { Tabela } 1 \text { (por exemplo: sistema estrutural mínimo } 50 \text { anos). } \\
\text { Quais Manutenções de Projeto você considera necessárias para } \\
\text { atingir os prazos de vida útil determinados para o seu tipo de } \\
\text { projeto? (Discursiva) }\end{array}$ \\
\hline 8 & $\begin{array}{l}\text { Quais especificações você está realizando atualmente em seus } \\
\text { memoriais a respeito da Manutenção de Projeto? (Discursiva) }\end{array}$ \\
\hline
\end{tabular}

Fonte: Os autores.

\section{Verificação de Fabricantes}

Finalizada a segunda etapa, foram selecionados alguns sistemas construtivos que compõe uma edificação habitacional, tendo como base o Anexo C da NBR 15575-1 (ABNT, 2013a), por estarem presentes em todas as edificações habitacionais e causar uma grande 
influência visual, sendo eles: pisos, revestimentos internos e externos e impermeabilização.

Para a análise de especificações de durabilidade e vida útil dos materiais foram pesquisados em listas de fabricantes as empresas líderes de mercado na fabricação dos materiais e produtos analisados. Deste modo, selecionaram-se um total de 11 fabricantes: 4 de pisos e revestimentos internos e externos aderidos (ex.: porcelanatos), 2 de revestimentos internos e externos não aderidos (ex.: lâmina de madeira), 3 de pinturas internas e externas e 2 de impermeabilização manutenível com e sem quebra de revestimento (ex.: manta asfáltica).

Primeiramente, buscou-se dados nas páginas da internet dos fabricantes, em páginas de especificações, manuais de utilização e boletins técnicos dos produtos. Quando não encontrados, entrou-se em contato via e-mail com o fornecedor e quando não houve resposta, realizou-se contato telefônico.

Após a montagem do banco de dados realizou-se a análise e interpretação dos resultados obtidos, buscandose avaliar a vida útil estipulada pelos fabricantes e compará-las aos períodos apresentados pela Norma de Desempenho.

Por fim, elaborou-se quadros contendo os dados obtidos para cada subsistema dos sistemas selecionados e estudados.

\section{Resultados}

\section{Análise dos questionários}

Ao encaminhar o questionário por e-mail para os 420 profissionais foram obtidas apenas oito respostas, ou seja, apenas $2 \%$ dos profissionais pesquisados responderam às perguntas aplicadas.

Após o contato telefônico com projetistas selecionados, investigou-se o motivo pelo qual não respondeu $o$ questionário, a justificativa apresentada pela maior parte dos entrevistados foi não ter conhecimento a respeito do assunto abordado. $\mathrm{O}$ fato é que os profissionais contatados revelaram que tinham conhecimento básico acerca da NBR 15575 e de manutenção rotineira, entretanto não conheciam acerca da expressão "manutenção de projeto", a qual se baseava a maior parte do questionário. Assim, por esse motivo, não se dispuseram a responder o questionário. Assim, averiguar essa falta de conhecimento dos profissionais acerca da manutenção rotineira e de projeto acabou sendo o principal resultado desse levantamento.

As respostas obtidas no levantamento online foram de 8 profissionais da área de projetos da construção civil. Nas respostas das questões diretas 1, 3 e 6 (Figura 1, 2 e 3, respectivamente), observou-se que $50 \%$ dos participantes consideraram as especificações da vida útil de projeto em alguns de seus trabalhos e $62 \%$ não sabem diferenciar manutenção de projeto e de rotina, porém $62 \%$ afirmaram especificar os materiais que atendem ao desempenho mínimo da edificação.

Figura 1 - Análise das respostas da questão 1 (na elaboração dos seus projetos, está realizando especificações considerando a vida útil de projeto?)

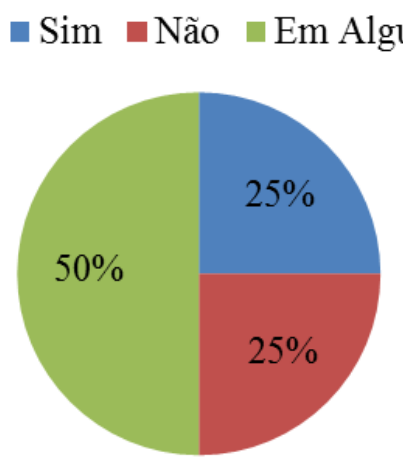

Fonte: Os autores

Figura 2 - Análise das respostas da questão 3 (em função dos projetistas estabelecerem quais materiais, produtos e processos atendem ao desempenho mínimo da edificação. Você está realizando alguma dessas especificações em seus memoriais descritivos?)

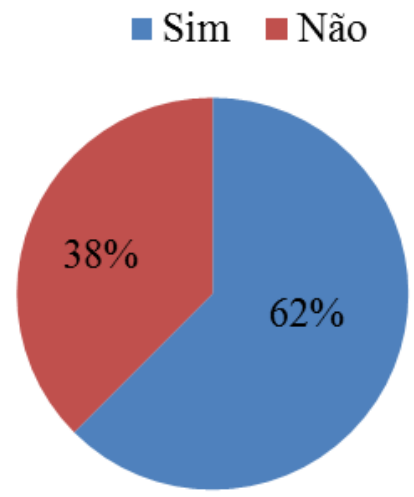

Fonte: Os autores

Figura 3 - Análise das respostas da questão 6 (você conhecia a diferença entre Manutenção de Projeto e a Manutenção de Rotina?)

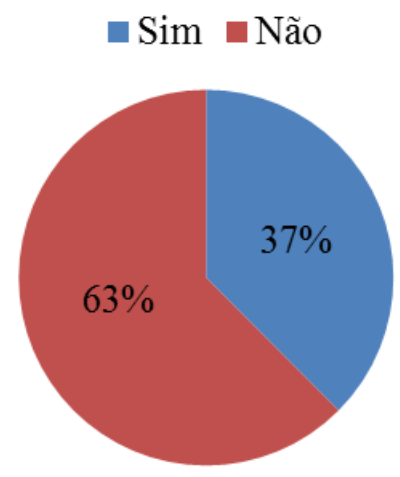

Fonte: Os autores.

Com relação às questões discursivas, observou-se que os projetistas têm conhecimento da existência da norma de desempenho, porém estão com grande dificuldade em atendê-la. Desta forma, optam por não realizar as 
especificações e, consequentemente, não atender aos prazos de vida útil, como uma forma de se ausentar das responsabilidades.

Esta dificuldade foi justificada pela falta de disponibilização das especificações de materiais por parte dos fabricantes. Outro fator é a resistência do cliente em optar somente por materiais que possuam a especificação do fabricante, independente do valor.

\section{Análise de memoriais e projetos}

Com o objetivo de complementar os entendimentos sobre as dificuldades dos projetistas em especificar $o$ desempenho e a vida útil obtidos na etapa anterior, foram analisados memoriais e projetos de alguns dos participantes do estudo para observar quais especificações foram realizadas com relação aos requisitos de manutenibilidade e manutenção dos sistemas.

Dentre os 5 memoriais e projetos disponibilizados foi possível constatar que os projetistas não estão realizando especificações de manutenção e não estão definindo a vida útil de projeto. Essa falta de especificação e detalhamento em projetos, para determinar ou definir desempenho e vida útil por parte dos projetistas, torna a construtora ou executora da obra dependente das especificações de desempenho e vida útil dos materiais por parte dos fabricantes dos produtos utilizados na obra.

\section{Especificações dos materiais pelos fabricantes}

Os sistemas selecionados para averiguar as informações dos fabricantes a respeito da vida útil de projeto conforme NBR 15575-1 (ABNT, 2013a) apresentam subdivisões em suas especificações de vida útil de projeto: os pisos são apenas externos; o revestimento interno é dividido em aderido, não aderido e pintura interna; o revestimento externo é dividido em aderido, não aderido e pintura externa; e por fim a impermeabilização é classificada em manutenível sem quebra de revestimentos e com quebra de revestimentos.

Primeiramente, foi verificada a vida útil mínima dos subsistemas, apresentadas pela norma de desempenho, sendo estas apresentadas no Quadro 2.

Esta pesquisa resultou na investigação de 11 fabricantes dos diversos sistemas selecionados. Em um primeiro momento foram verificadas se as informações estavam disponíveis nas páginas da internet das empresas, sendo encontradas especificações de vida útil dos produtos em 4 páginas da internet de fabricantes. Para os outros 7 fabricantes que não dispunham de informações em páginas da internet foram encaminhados e-mails interrogando-os, porém obteve-se apenas uma resposta. Desta maneira entrou-se em contato por meio telefônico interrogando o fabricante, porém todos os 6 restantes confirmaram que não especificam a vida útil de seus produtos.

\begin{tabular}{|c|c|c|c|}
\hline $\begin{array}{l}\text { Sistema da } \\
\text { Edificação }\end{array}$ & Subdivisão do Sistema & $\begin{array}{l}\text { Vida Útil } \\
\text { NBR } \\
15575\end{array}$ & \begin{tabular}{|c|} 
Vida Útil \\
Informada por \\
Fabricantes \\
\end{tabular} \\
\hline Pisos & Pisos Externos & 13 anos & $\begin{array}{c}13 \text { anos } \\
\text { (3 fabricantes) }\end{array}$ \\
\hline \multirow{3}{*}{$\begin{array}{l}\text { Revestimento } \\
\text { Interno }\end{array}$} & $\begin{array}{c}\text { Revestimento Interno } \\
\text { Aderido }\end{array}$ & 13 anos & $\begin{array}{c}13 \text { anos } \\
\text { (3 fabricantes) } \\
\end{array}$ \\
\hline & $\begin{array}{l}\text { Revestimento Interno } \\
\text { não Aderido }\end{array}$ & 8 anos & $\begin{array}{c}12 \text { anos } \\
\text { (1 fabricante) }\end{array}$ \\
\hline & Pintura Interna & 3 anos & Não Informam \\
\hline \multirow{3}{*}{$\begin{array}{l}\text { Revestimento } \\
\text { Externo }\end{array}$} & $\begin{array}{l}\text { Revestimento Externo } \\
\text { Aderido }\end{array}$ & 20 anos & $\begin{array}{c}20 \text { anos } \\
\text { (3 fabricantes) }\end{array}$ \\
\hline & $\begin{array}{l}\text { Revestimento Externo } \\
\text { não Aderido }\end{array}$ & 20 anos & $\begin{array}{c}20 \text { anos } \\
\text { (1 fabricante) }\end{array}$ \\
\hline & Pintura Externa & 8 anos & Não Informam \\
\hline \multirow{2}{*}{ Impermeabilização } & $\begin{array}{c}\text { Impermeabilização } \\
\text { Manutenível sem Quebra } \\
\text { de Revestimento }\end{array}$ & 4 anos & $\begin{array}{c}10 \text { anos } \\
\text { (1 fabricante) }\end{array}$ \\
\hline & $\begin{array}{c}\text { Impermeabilização } \\
\text { Manutenível com Quebra } \\
\text { de Revestimento }\end{array}$ & 8 anos & Não Informam \\
\hline
\end{tabular}

Fonte: Adaptado de Anexo C da NBR 15575-1 (ABNT, 2013a)

Primeiramente, foi verificada a vida útil mínima dos subsistemas, apresentadas no Anexo C da NBR 15575-1 (ABNT, 2013a) e também as determinadas pelos fabricantes pesquisados, sendo estas apresentadas no Quadro 2, juntamente com o número de fabricantes entrevistados que especificam este período de vida útil.

No Quadro 2 observa-se que não houve divergências com relação ao tempo de vida útil informado pelos fabricantes, porém nem todos os fabricantes questionados disponibilizavam este prazo, conforme será detalhado nos quadros apresentados na sequência.

Dos 11 fabricantes investigados, 4 (A, B, C, D) são fornecedores de pisos externos e revestimentos internos e externos aderidos. Conforme se pode observar no Quadro 3 , apenas um fornecedor dos 4 não informa a vida útil de seus produtos.

Quadro 3 - Vida Útil do sistema de pisos e revestimento interno e externo aderido especificado pelos fabricantes

\begin{tabular}{|c|c|c|c|c|c|c|}
\hline \multirow{2}{*}{$\begin{array}{l}\text { Sistema da } \\
\text { Edificação }\end{array}$} & \multirow{2}{*}{$\begin{array}{l}\text { Subdivisão } \\
\text { do Sistema }\end{array}$} & \multirow{2}{*}{$\begin{array}{c}\text { Vida } \\
\text { Útil } \\
\text { NBR } \\
15575 \\
\end{array}$} & \multicolumn{4}{|c|}{ Vida Útil Fabricantes } \\
\hline & & & A & B & C & D \\
\hline Pisos & $\begin{array}{c}\text { Pisos } \\
\text { Externos }\end{array}$ & $\begin{array}{c}13 \\
\text { anos }\end{array}$ & $\begin{array}{c}13 \\
\text { anos }\end{array}$ & $\begin{array}{c}\text { Não } \\
\text { Informa }\end{array}$ & $\begin{array}{c}13 \\
\text { anos }\end{array}$ & $\begin{array}{c}13 \\
\text { anos }\end{array}$ \\
\hline $\begin{array}{l}\text { Revestimento } \\
\text { Interno }\end{array}$ & $\begin{array}{c}\text { Revestimento } \\
\text { Interno } \\
\text { Aderido } \\
\end{array}$ & $\begin{array}{c}13 \\
\text { anos }\end{array}$ & $\begin{array}{c}13 \\
\text { anos }\end{array}$ & $\begin{array}{c}\text { Não } \\
\text { Informa }\end{array}$ & $\begin{array}{c}13 \\
\text { anos }\end{array}$ & $\begin{array}{c}13 \\
\text { anos }\end{array}$ \\
\hline $\begin{array}{l}\text { Revestimento } \\
\text { Externo }\end{array}$ & $\begin{array}{c}\text { Revestimento } \\
\text { Externo } \\
\text { Aderido }\end{array}$ & $\begin{array}{c}20 \\
\text { anos }\end{array}$ & $\begin{array}{c}20 \\
\text { anos }\end{array}$ & $\begin{array}{c}\text { Não } \\
\text { Informa }\end{array}$ & $\begin{array}{c}20 \\
\text { anos }\end{array}$ & $\begin{array}{c}20 \\
\text { anos }\end{array}$ \\
\hline
\end{tabular}

Fonte: Os autores. 
Outro detalhe importante é o período de vida útil determinado pelos fabricantes, sendo que nestes sistemas todos os fornecedores especificaram períodos dentro do limite mínimo determinado pela norma.

Com relação aos sistemas de revestimento interno e externo não aderido foram investigados dois fabricantes, entre eles um não informa as especificações de vida útil de seus produtos. Conforme pode ser observado no Quadro 4, o fabricante que está realizando a especificação de seus produtos está de acordo com o período de vida útil determinado pela norma de desempenho.

Os revestimentos internos e externos também podem apresentar o subsistema de pintura interna e externa, respectivamente. Para estes sistemas foram investigadas 3 empresas fabricantes de tintas, porém nenhuma das empresas informa o tempo de vida útil mínimo de seus produtos.

Quadro 4 - Vida Útil do sistema de revestimento interno e externo não aderido especificado pelos fabricantes

\begin{tabular}{|c|c|c|c|c|}
\hline \multirow{2}{*}{ Sistema da Edificação } & \multirow{2}{*}{$\begin{array}{l}\text { Subdivisão } \\
\text { do Sistema }\end{array}$} & \multirow{2}{*}{$\begin{array}{c}\text { Vida } \\
\text { Útil } \\
\text { NBR } \\
15575\end{array}$} & \multicolumn{2}{|c|}{$\begin{array}{c}\text { Vida Útil } \\
\text { Fabricantes }\end{array}$} \\
\hline & & & E & $F$ \\
\hline Revestimento Interno & $\begin{array}{l}\text { Revestimento } \\
\text { Interno não } \\
\text { Aderido }\end{array}$ & 8 anos & $\begin{array}{c}\text { Não } \\
\text { Informa }\end{array}$ & 12 anos \\
\hline Revestimento Externo & $\begin{array}{l}\text { Revestimento } \\
\text { Externo não } \\
\text { Aderido }\end{array}$ & 20 anos & $\begin{array}{c}\text { Não } \\
\text { Informa }\end{array}$ & 20 anos \\
\hline
\end{tabular}

Fonte: Os autores.

Para o sistema de impermeabilização, dividido em manutenível com e sem quebra de revestimento, foram investigadas 2 empresas fabricantes (dentre as 3 disponíveis na região), porém ambas não informam o tempo de vida útil mínimo para o produto de impermeabilização com quebra de revestimento (Quadro 5). Para os produtos de impermeabilização manutenível sem quebra de revestimento, um dos fabricantes determina um período adequado de vida útil, segundo a NBR 15575.

Quadro 5 - Vida Útil do sistema de impermeabilização especificada pelos fabricantes

\begin{tabular}{|c|c|c|c|c|}
\hline \multirow{2}{*}{ Sistema da Edificação } & \multirow{2}{*}{$\begin{array}{c}\text { Subdivisão do } \\
\text { Sistema }\end{array}$} & $\begin{array}{c}\text { Vida } \\
\text { UBil }\end{array}$ & \multicolumn{2}{|c|}{$\begin{array}{c}\text { Vida Útil } \\
\text { Fabricantes }\end{array}$} \\
\cline { 3 - 5 } & $\mathbf{1 5 5 7 5}$ & $\mathbf{J}$ & $\mathbf{K}$ \\
\hline Impermeabilização & $\begin{array}{c}\text { Impermeabilização } \\
\text { Manutenível com } \\
\text { Quebra de } \\
\text { Revestimento }\end{array}$ & 8 anos & $\begin{array}{c}\text { Não } \\
\text { Informa }\end{array}$ & $\begin{array}{c}\text { Não } \\
\text { Informa }\end{array}$ \\
\hline & $\begin{array}{c}\text { Impermeabilização } \\
\text { Impermeabilização } \\
\text { Quebrel sem } \\
\text { Revestimento }\end{array}$ & 4 anos & 10 anos & $\begin{array}{c}\text { Não } \\
\text { Informa }\end{array}$ \\
\hline
\end{tabular}

Fonte: Os autores.
Ao observar os resultados obtidos com a pesquisa de vida útil informada por fabricantes, percebe-se que 9 de 19 fabricantes não fornecem a vida útil dos seus produtos (Quadros 2, 3, 4 e 5), o que equivale a dizer que 47\%, ou a média, dos fabricantes consultados não fornecem a vida útil de seus produtos. Entretanto, este comportamento diverge entre os tipos de subsistemas analisados. É mais evidente nos subsistemas de pintura externa e interna, impermeabilização manutenível sem e com quebra de revestimento e revestimento interno e externo não aderido.

Porém, cabe destacar que alguns fabricantes de produtos de impermeabilização estão aderindo às definições da norma, isso se confirma ao verificar que as empresas que apresentam especificações de vida útil estão cumprindo os prazos mínimos impostos pela norma de desempenho (Quadro 5).

\section{Considerações finais}

A pesquisa realizada buscou, primeiramente, averiguar o conhecimento de projetistas a respeito das especificações dos sistemas construtivos utilizados em seus projetos e memoriais. Na região estudada, Oeste de Santa Catarina, obteve-se um baixo índice de retorno da pesquisa. Conjectura-se este fato pela falta de conhecimento dos projetistas acerca da expressão "manutenção de projeto" da norma de desempenho ou pela falta de interesse no tema. Porém, qualquer que seja a razão, isto traz preocupação por se tratar de um tema de extrema importância.

Da mesma forma, os memoriais analisados demonstram a falta de preocupação ou de conhecimento nas questões de vida útil ou desempenho. Observou-se que a responsabilidade do projetista em determinar o período de vida útil dos produtos, materiais e processos é totalmente dependente dos fabricantes, e é obrigação destes informar aos clientes e usuários de seus produtos as respectivas informações de desempenho e vida útil.

Foi identificado um efeito cascata. $O$ projetista não informa o desempenho e vida útil porque não se apropriou por completo da norma de desempenho ou para não se comprometer por escolhas de clientes, o que transfere ao construtor a responsabilidade desta informação baseado no que está sendo construído, o que leva a uma dependência de obter estas informações dos fornecedores e os fornecedores, dependendo do subsistema, ainda não estão informando.

Como resultado final verificou-se que $47 \%$ dos fabricantes que participaram desta pesquisa ainda não estão determinando a vida útil nem procedimentos necessários para a garantia de desempenho. Isto dificulta o desenvolvimento adequado das atividades dos 
projetistas perante a norma, em especificar os materiais que estão utilizando, de acordo com sua durabilidade e vida útil.

Saliente-se que esses resultados não podem ser extrapolados para uma conjuntura nacional, pois se trata de pesquisa regional. Em função disso, sugere-se a replicação deste estudo de campo em outras regiões do país e também a avaliação de mais subsistemas.

\section{Agradecimentos}

Agradecemos ao financiamento do PIBIC/FAPE da Universidade Comunitária da Região de Chapecó (Unochapecó).

\section{Referências}

ABNT - ASSOCIAÇÃO BRASILEIRA DE NORMAS TÉCNICAS. NBR 15575-1: Edificações habitacionais - Desempenho, Parte 1: Requisitos gerais. Rio de Janeiro, 2013a.

ABNT - ASSOCIAÇÃO BRASILEIRA DE NORMAS TÉCNICAS. NBR 15575-2: Edificações habitacionais - Desempenho, Parte 2: Requisitos para os sistemas estruturais. Rio de Janeiro, $2013 \mathrm{~b}$.

ABNT - ASSOCIAÇÃO BRASILEIRA DE NORMAS TÉCNICAS. NBR 15575-3: Edificações habitacionais - Desempenho, Parte 3: Requisitos para os sistemas de pisos. Rio de Janeiro, 2013c.

ABNT - ASSOCIAÇÃO BRASILEIRA DE NORMAS TÉCNICAS. NBR 15575-4: Edificações habitacionais - Desempenho, Parte 4: Sistemas de vedações verticais internas e externas. Rio de Janeiro, 2013d.

ABNT - ASSOCIAÇÃO BRASILEIRA DE NORMAS TÉCNICAS. NBR 15575-5: Edificações habitacionais - Desempenho, Parte 5: Requisitos para sistemas de coberturas. Rio de Janeiro, 2013e.

ABNT - ASSOCIAÇÃO BRASILEIRA DE NORMAS TÉCNICAS. NBR 15575-6: Edificações habitacionais - Desempenho, Parte 6: Sistemas hidrossanitários. Rio de Janeiro, 2013f.

ABNT - ASSOCIAÇÃO BRASILEIRA DE NORMAS TÉCNICAS. NBR 5674: Manutenção de edificações - Procedimento. Rio de Janeiro, 1999.

CBIC - CÂMARA BRASILEIRA DA INDÚSTRIA DA CONSTRUÇÃO. Desempenho de Edificações Habitacionais: guia orientativo para atendimento à norma ABNT NBR 15575/2013. Fortaleza: Gadioli Cipolla Comunicação, 2013.

CBIC - CÂMARA BRASILEIRA DA INDÚSTRIA DA CONSTRUÇÃO. Dúvidas sobre a norma de desempenho: especialistas respondem às principais dúvidas e elencam requisitos de suportes para elaboração de projetos. Brasilia: CBIC, 2015.

CHEVAlieR, J.; SJOSTROM, C.; TRINIUS, W.; JASUJA, M. Life Performance of Construction Materials and Components. Rotterdam: CIB, 2005. 61 p. (Final Report, Performance Based Building Thematic Network - PeBBu Domain 1). Disponível em: $\langle$ http://www.irbnet.de/daten/iconda/CIB22200.pdf >. Acesso em: 10.05.2018.

DANIOTTI, B.; SPAGNOLO, S. L. Service Life Estimation Using Reference Service Life Databases and Enhanced Factor Method. In: INTERNATIONAL CONFERENCE ON DURABILITY OF BUILDINGS MATERIALS AND COMPONENTS, 11, 2008, Istanbul. Proceedings... Istanbul: DBMC, 2008.

DEL MAR, C. P. Direito na Construção Civil. São Paulo: Pini: Leud, 2015.

FREITAS, L. S.; SCHMID, A. L.; SILVA, R. C. A Tomada de Decisão na Previsão da Vida Útil de Projeto para Edificações mais sustentáveis. In: ENCONTRO NACIONAL DE TECNOLOGIA DO AMBIENTE CONSTRUÍDO, 16, São Paulo. Anais... Porto Alegre: ANTAC, 2016.

HERNÁNDEZ-MORENO, S. Aplicación de la Información de la Vida Útil em la Planeación y Diseño de Proyectos de Edificación. Acta Universitaria. Universidad de Guanajuato, v. 21, n. 2, 2011. Disponível em: 〈http://hdl.handle.net/20.500.11799/39189>. Acesso em: 13.05.2018. 
LACASSE, M. A.; SJOSTROM, C. Recent advances in methods for service life prediction of building materials and components an overview. In: CIB WORLD BUILDING CONGRESS, 16, 2004, Toronto. Proceedings... Delft: CIB, 2004.

OLIVEIRA, Luciana Alves; FONTENELLE, João Heitzmann; MITIDIERI FILHO, Claudio Vicente. Durabilidade de fachadas: método de ensaio para verificação da resistência à ação de calor e choque térmico. Ambient. constr., Porto Alegre , v. 14, n. 4, p. 53-67, Dec. 2014. doi:http://dx.doi.org/10.1590/S1678-86212014000400005.

ORTEGA MADRIGAL, Leticia; SERRANO LANZAROTE, Begoña; FRAN BRETONES, José M. Proposed method of estimating the service life of building envelopes. Revista de la Construcción, Santiago, v. 14, n. 1, p. 60-68, Apr. 2015. doi:http://dx.doi.org/10.4067/S0718-915X2015000100008.

PEÇAS, P.; RIBEIRO, I.; SILVA, A.; HENRIQUES, E. Comprehensive approach for informed life cycle-based materials selection. Materials \& Design, v. 43, n. 1, p. 220-232, jan. 2013. doi:https://doi.org/10.1016/j.matdes.2012.06.064.

POSSAN, E.; DEMOLINER, C. A. Desempenho, Durabilidade e Vida Útil das Edificações: abordagem geral. Revista TécnicoCientifica do CREA-PR, v. 1, n. 1, p. 93-111, 2013. Disponível em: <http://creaprw16.creapr.org.br/revista/Sistema/index.php/revista/article/view/14>. Acesso em: 10.05.2018

SANCHES, I. D.; FABRICIO, M. M. Projeto para Manutenção. In: WORKSHOP BRASILEIRO DE GESTÃO DO PROCESSO DE PROJETOS NA CONSTRUÇÃO DE EDIFÍCIOS, 8, São Paulo. Anais... São Paulo: POLI-USP, 2008.

SANTOS, F. M. Á. S.; HIPPERT, M. A. S. Gestão da Manutenção e a NBR 15.575/2013. In: ENCONTRO NACIONAL DE TECNOLOGIA DO AMBIENTE CONSTRUÍDO, 16, São Paulo. Anais... Porto Alegre: ANTAC, 2016.

SANTOS, M. R. P. Metodologias de Previsão da Vida Útil de Materiais, Sistema ou Componentes da Construção. 2010.129 f. Dissertação (Mestrado em Engenharia Civil - Especialização em Construção) - Faculdade de Engenharia. Universidade do Porto, Porto, 2010. Disponível em: <http://hdl.handle.net/10216/60309>. Acesso em: 13.05.2018.

SANTOS, V. J. Construção Civil: análise da normativa NBR 15.575 à luz do Código do Consumidor. Porto Alegre, 2011. Disponível em: <http://www.espaco-vital.jusbrasil.com.br/noticias〉. Acesso em: 05.12.2014.

STRAUB, A. D. Using the Factor Method to get Realistic Service Lives of Applies Building Components. In: JOINT CIB W070, W092,\& WTG72 INTERNATIONAL CONFERENCE ON FACILITIES MANAGEMENT, PROCUREMENT SYSTEMAS AND PUBLIC PRIVATE PARTNERSHIP, 2012, Cape Town. Proceedings...Delft:CIB, 2012. Disponível em: < http://www.irbnet.de/daten/iconda/CIB_DC24053.pdf>. Acesso em: 10.05.2018.

ZARZAR JÚNIOR, F. C. Metodologia para estimar a Vida Útil de elementos construtivos, baseada no Método dos Fatores. 2007. 173 f. Dissertação (Mestrado em Engenharia Civil) - Universidade Católica de Pernambuco, Recife, 2007.

\footnotetext{
${ }^{1}$ Claudivana Sistherenn Pagliari

Engenheiro Civil. Graduação em Engenharia Civil. Endereço Postal: Av. Senador Atílio Fontana, 591-E, Chapecó, SC, Brasil, 89.809-000
}

\author{
${ }^{2}$ Marcelo Fabiano Costella \\ Engenheiro Civil. Doutor em Engenharia de Produção. Endereço Postal: Av. Senador Atílio Fontana, 591-E, Chapecó, SC, Brasil, \\ 89.809-000
}

\title{
${ }^{3}$ Sílvio Edmundo Pilz
}

Engenheiro Civil. Mestre em Engenharia Civil. Endereço Postal: Av. Senador Atílio Fontana, 591-E, Chapecó, SC, Brasil, 89.809000 